\title{
O problema da diferença antropológica na fenomenologia de Etienne Bimbenet
}

\section{The problem of the anthropological difference in the phenomenology of Etienne Bimbenet}

\section{El problema de la diferencia antropológica en la fenomenología de Etienne Bimbenet}

\author{
Pedro Henrique Santos Decanini Marangoni ${ }^{a}{ }^{(\mathbb{D}}$; Danilo Saretta Verissimo $^{\text {b }}$ (D) \\ ${ }^{\text {a }}$ Doutorando do Programa de Pós-Graduação em Psicologia da Faculdade de Ciências e Letras de Assis da UNESP. Universidade \\ Estadual Paulista Júlio de Mesquita Filho, Assis, SP, Brasil - E-mail: pedro.marangoni@yahoo.com.br \\ ${ }^{\text {b }}$ Docente do Departamento de Psicologia Social e Educacional e do Programa de Pós-Graduação em Psicologia da Faculdade de \\ Ciências e Letras de Assis da UNESP. Universidade Estadual Paulista Júlio de Mesquita Filho, Assis, SP, Brasil - E-mail: \\ danilo.verissimo@gmail.com
}

Resumo: Neste artigo apresentamos e discutimos as reflexões realizadas por Etienne Bimbenet (2011/2014) e Maurice Merleau-Ponty (1942/2006) em torno do problema da diferença antropológica, referente à comparação entre os comportamentos humanos e animais. Para estes autores, a ordem humana inaugura uma nova estrutura de comportamentos em relação à ordem vital. Tanto Merleau-Ponty como Bimbenet entendem que a vida animal e a vida humana são ordens originais que apresentam modos específicos de interação com o ambiente. A experiência animal nos revela uma orientação comportamental ditada por valores funcionais específicos que selecionam os estímulos dotados de um sentido para o organismo. Contudo, os autores reconhecem que a percepção humana é essencialmente distinta desta lógica de funcionamento, visto que a capacidade de desprendimento do próprio ponto de vista em direção a um mundo intersubjetivo constitui-se como o traço fundamental da experiência humana.

Palavras-chave: Animalidade. Bimbenet. Humano. Merleau-Ponty. Percepção.

\begin{abstract}
In this paper we present and discuss the reflections made by Etienne Bimbenet (2011/2014) and Maurice Merleau-Ponty (1942/2006) on the problem of anthropological difference, regarding the comparison between human behavior and animals. For these authors, the human order opens a new structure behavior in relation to the vital order. Both Merleau-Ponty as Bimbenet understand that animal life and human life are original orders that have specific modes of interaction with the environment. Animal experience reveals a behavioral orientation dictated by specific functional values that select the stimuli provided with a sense for the body. However, the authors acknowledge that human perception is essentially different from this operating logic, since the capacity of releasing itself from it's own point of view towards an inter-subjective world is the fundamental feature of human experience.
\end{abstract}

Keywords: Animality. Bimbenet. Human. Merleau-Ponty. Perception. 
Resumen: En este artículo presentamos y discutimos las reflexiones hechas por Etienne Bimbenet (2011/2014) y Maurice Merleau-Ponty (1942/2006) sobre el problema de la diferencia antropológica, en relación con la comparación entre el comportamiento humano y los animales. Para estos autores, el orden humano abre una nueva estructura de comportamiento en relación con el orden vital. Tanto Merleau-Ponty como Bimbenet entienden que la vida animal y la vida humana son órdenes originales que tienen modos específicos de interacción con el medio ambiente. La experiencia animal revela una orientación conductual dictada por valores funcionales específicos que seleccionan los estímulos proporcionados con un sentido para el cuerpo. Sin embargo, los autores reconocen que la percepción humana es esencialmente diferente de esta lógica operativa, ya que la capacidad de liberarse de su propio punto de vista hacia un mundo intersubjetivo es la característica fundamental de la experiencia humana.

Palabras clave: Animal. Bimbenet. Humano. Merleau-Ponty. Percepción.

\section{Como citar o artigo:}

MARANGONI, P. H. S. D. VERISSIMO, D. S. O problema da diferença antropológica na fenomenologia de Etienne Bimbenet. Revista de Ciências Humanas, v.52, 2018. DOI: 10.5007/2178-4582.2018.47324

\section{INTRODUÇÃO}

Ao longo da filosofia de Merleau-Ponty, o tema da animalidade é trabalhado de maneira esporádica, sobretudo, porque o objetivo principal do filósofo é fornecer contornos mais precisos acerca da percepção humana. Neste sentido, Em A Estrutura do Comportamento, sua primeira obra, as considerações realizadas em torno da animalidade, presentes em praticamente o livro inteiro, cumprem a função de auxiliar o autor a redefinir as relações entre consciência e natureza. A partir da tese de que os comportamentos animais não são desdobramentos mecânicos de processos causais, o autor elabora uma definição estrutural da natureza. Desde o âmbito físico, passando pela ordem vital, até culminar na ordem humana, a natureza organiza-se como um processo dinâmico, global e autônomo. Em cada uma destas ordens, no entanto, os processos de organização variam. Em um sistema físico, por exemplo, as interações entre as condições topográficas (internas) e as forças externas visam, invariavelmente, manter uma condição de equilíbrio interno. $\mathrm{Na}$ ordem vital, o comportamento atua como seletor dos estímulos aos quais o organismo responderá. A percepção animal seleciona seus objetos de atenção de acordo com suas normas vitais. Apesar de cada ordem incorporar aspectos da ordem precedente, esta análise estrutural proposta por Merleau-Ponty tem como objetivo principal reconhecer a originalidade implícita a cada forma de organização. Assim, no tocante à vida humana a percepção revela-se radicalmente diferente da experiência animal. Neste ponto de transição descritiva entre a ordem vital e a ordem humana, aparece no livro do filósofo a noção de perspectivismo. Nosso objetivo é evidenciar a forma como Etienne Bimbenet se apropria desta inovação conceitual a utilizando para levar a cabo uma descrição fenomenológica da diferença antropológica. 


\section{NATURALISMO E HUMANISMO}

A questão da diferença entre os comportamentos animais e humanos oscila entre dois polos principais: a verdade do fato evolutivo e o caráter de exceção humana imputado pelo humanismo. Assumir um destes princípios requer, evidentemente, a negação do outro. Há, nesse sentido, uma ambigüidade imanente ao tema da diferença antropológica. Como conciliar a evolução, o ponto de vista da nossa animalidade, com a ideia de que o fenômeno humano é essencialmente distinto da ordem vital?

De um lado, o naturalismo do fato evolutivo nos aparece como um argumento irrefutável, dada sua constatação empírica. A ciência do último século apresentou evidências que testemunham a favor da hipótese de uma continuidade inter-espécies. O discurso científico pressupõe, desde o nível genético até o aparecimento dos comportamentos sociais, uma diferença de grau e não de natureza entre a vida humana e a animal. De fato, a biologia molecular corrobora a tese da continuidade ao afirmar que os processos de transmissão de material genético são os mesmos, desde os organismos unicelulares até o ser humano. Nota-se que o discurso da continuidade também está presente no que diz respeito às funções cognitivas. As ciências cognitivas afirmam que os fenômenos de recepção, armazenamento e processamento de informação são mais complexos nos seres-humanos do que nos animais, por conta de processos de refinamento cognitivo. Em última análise, os processos são os mesmos. Nessa medida, a própria sociabilidade humana tem seu fundamento primeiro em comportamentos mais primitivos, como os de cooperação, aliança e imitação. Por outro lado, o humanismo acredita que do fato evolutivo origina-se uma existência de direito. Os seres-humanos reconhecem a seus congêneres uma empatia que é diferente da empatia para com os animais. A vida humana torna-se sacralizada, absoluta e, portanto, mais imponente. Ainda que se reconheça a necessidade de uma ética para com os animais, os valores atribuídos ao vivente animal não se equiparam àqueles estabelecidos para os seres-humanos. É necessário encarar estas duas verdades: a absolutidade de nossa proveniência natural e, ao mesmo tempo, nossa distância irredutível em relação ao animal.

Neste cenário, a obra de Etienne Bimbenet, "O animal que não sou mais" (2014), emerge de maneira disruptiva frente às propostas naturalistas e humanistas. A tese sustentada pelo autor, assim como em grande parte da tradição fenomenológica, é a de que "o homem não é mais um animal" (BIMBENET, 2014, p.26). Esta tese afronta diretamente as narrativas naturalistas e humanistas, justamente na medida em que ela se estabelece na intersecção entre a verdade do fato evolutivo, evidência de nossa "proveniência natural", e a constatação vivida de uma diferença superlativa entre os comportamentos humanos e animais. "Claro, o homem foi um animal, entretanto ele não o é mais. 
Ele está privado de sua origem animal, no sentido em que Heidegger dava a este termo: vivendo com ela, e, entretanto, sem ela" (BIMBENET, 2014, p.27). Lembremos do importante ensinamento de Merleau-Ponty: é preciso afirmar a diferença não no âmbito de uma filosofia da substância, que justapõe razão e corpo, e sim, no terreno de uma diferença funcional. Ao se reconhecer a dimensão intencional que vivifica a percepção animal deve-se renunciar a uma definição maquinal dos viventes não-humanos. Se os animais não são máquinas regidas pelas mesmas leis de outros sistemas físicos, o ser-humano tampouco é o resultado de um suporte corporal, "o lado animal", acrescido de uma substância pensante, que viria a ser o caractere propriamente humano. Com efeito, o problema da diferença antropológica somente se liberta dos dualismos metafísicos (corpo/alma, sensível/inteligível) se entendermos que esta diferença é estrutural e está vinculada à dimensão funcional da experiência perceptiva, ou seja, ao comportamento. Sob o preceito de uma diferença estrutural, somos conduzidos a responder as seguintes perguntas: o que significa perceber como um animal e, o que significa perceber como um humano?

\section{A LÓGICA DO UNO: A FENOMENOLOGIA DA ANIMALIDADE}

A influência de Merleau-Ponty é decisiva e evidente no texto de Bimbenet, sobretudo, porque o dispositivo conceitual utilizado para se balizar a comparação entre os comportamentos humanos e animais é, precisamente, o conceito de perspectivismo. O interesse da fenomenologia contemporânea em uma tal questão é compreender o que significa, eideticamente, perceber o mundo como animal e como ser-humano. Um dos principais ancestrais do raciocínio fenomenológico de Bimbenet consiste na obra inicial de Merleau-Ponty, A Estrutura do Comportamento. Ao passo que este livro não é considerado, propriamente, uma obra fenomenológica, $O$ animal que não sou mais, por sua vez, pauta-se, explicitamente, na fenomenologia como método de análise da diferença entre os comportamentos animais e humanos. Esta preferência metodológica não exclui a validade das hipóteses cientificas. Mas, deve-se notar que a fenomenologia "visa um outro tipo de verdade" (BIMBENET, 2014, p.31). De modo geral, assume-se, na fenomenologia, o ponto de vista em primeira pessoa, referente ao sujeito da experiência. Não é do interesse da fenomenologia explicar empiricamente os fenômenos, por mais que tais explicações sejam utilizadas para validar certas posições fenomenológicas.

[...] o ponto de vista que ela [a fenomenologia] adota não é aquele das ciências da natureza; ele não é o ponto de vista exterior da observação empírica e da análise causal. A fenomenologia aborda os mesmos fenômenos, mas a partir do si mesmo, não descrevendo o que qualquer um poderia constatar e discutir, mas sobretudo que somente eu posso fazer a experiência (BIMBENET, 2014, p. 31) 
O que implica, nesse sentido, uma fenomenologia da animalidade? Como a noção de perspectivismo torna-se o centro de uma filosofia que tem como tese a diferença estrutural entre os comportamentos animais e humanos?

De acordo com Bimbenet, na esteira de Merleau-Ponty, o animal modula seu ambiente conforme suas capacidades orgânicas e suas normas vitais, de modo que o meio não se limita ao conjunto de estimulações físicas que circundam o organismo. Apesar do ambiente geográfico (Umgebung) representar a totalidade do entorno, ele não representa o meio comportamental do animal. O vivente possui a peculiar característica de selecionar, entre todos os estímulos presentes, aqueles que de alguma forma "contam” para si. Assim, a vida animal interpela apenas aquilo que já fora antecipado por suas normas próprias. "Viver, para um animal, é viver no meio de seu meio, no centro de um círculo polarizado pelas suas necessidades" (BIMBENET, 2014, p.103) ${ }^{1}$. A centralização do ambiente constitui, nessa medida, a essência mesma do viver animal.

Se existe efetivamente uma característica que pertença irredutivelmente ao vivente e que o defina de maneira própria é a de ser si mesmo o sujeito de sua vida. Um vivente é um centro de perspectiva, um ser a quem acontecem coisas e que se sente concernido pelo que lhe acontece. Um vivente está, por definição, no centro de sua vida (BIMBENET, 2014, p.33)

Exploremos a fenomenologia da animalidade proposta por Bimbenet com base em duas afirmações: "somente existe subjetividade animal, o animal é o único verdadeiro sujeito" (BIMBENET, 2014, p.103), e "o ponto de vista do animal é um ponto de vista absoluto, o único e verdadeiro perspectivismo" (BIMBENET, 2014, p.107). O emprego do termo "subjetividade" tem o propósito de destacar que a vida animal não é nada além desta atuação constante e seletiva, que faz emergir um meio próprio a partir de significações vitais precisas. Neste ponto, a essência prática da intencionalidade torna-se clara, pois não se trata, indica Bimbenet (2014), de intelectualizar a interação organismo/ambiente. Além disso, se a noção de subjetividade pode remeter ao aspecto cognoscente do viver animal, segundo um outro viés, pode-se objetar que o uso do termo "sujeito" demarca uma zona fronteiriça, porém intocável, entre aquilo que é interior e exterior, implicando uma forma de isolamento, pela qual o animal estaria fadado a um ciclo de autoafetação fechado em-si.

O conceito de subjetividade empregado por Bimbenet não circula por nenhuma das definições anteriores. Entendida segundo a noção de intencionalidade, a subjetividade animal aparece como um movimento que se efetiva "na e através de sua relação intencional a um meio, ela não é nada mais nem nada menos, em todo rigor, que esta própria relação, uma totalização ativa do ambiente que

\footnotetext{
${ }^{1}$ Esta seletividade atuante no interior da percepção animal proporciona, segundo Bimbenet, uma eficácia comportamental. Quanto maior for o grau de determinação da ação segundo fatores específicos - térmicos, dinâmicos, olfativos- menor será a riqueza dos comportamentos. "O animal é um ser seguro; ele somente percebe sobre o que ele pode agir, seu ambiente é conjunto de coisas que interessam sua ação” (BIMBENET, 2014, p. 104).
} 
coincide com a totalização de si mesmo" (BIMBENET, 2014, p. 105). Deste modo, a atividade dos organismos é inteiramente pautada pela busca em atualizar sua essência, ou seja, manter ativos e óptimos os fatores que possibilitam uma ação eficaz. A atividade não se realiza apenas de acordo com as regras internas de manutenção da existência corporal, mas toda ação expressa um movimento global do organismo para conservar sua essência. Esta "autoafirmação de uma essência" (BIMBENET, 2014, p.106), diferente das condutas de sobrevivência, não busca isolar-se das perturbações externas, pelo contrário, almeja um posicionamento ativo perante elas. Por isto Bimbenet se refere a esta atualização da essência como "autoafirmação de si".

Esta antecipação, com respeito ao seu entorno, disso que convém ao organismo, esta prefiguração do ambiente em função de suas necessidades, esta decisão essencial de unicamente perceber o próprio a si mesmo, definem então exatamente a subjetividade animalo 'si' da autoafirmação de si (BIMBENET, 2014, p.106)

A interpretação da percepção animal em um registro intencional atesta que o ambiente comportamental não é idêntico ao ambiente físico. Por mais que o último contenha o primeiro, compondo-se como fundo sob o qual é possível um meio específico aparecer, observa-se que, na linha de uma fenomenologia da animalidade, o campo do aparecimento não é o conjunto das excitações físicas que atingem o organismo, e sim, é um campo fenomenal radicalmente subjetivado por este. Contra essa objetivação do aparecer, disseminada pela reflexologia, e pelo vitalismo, por exemplo, Bimbenet resgata a análise estrutural posta em movimento por Merleau-Ponty em sua primeira obra. A noção de ordem utilizada pelo autor em A Estrutura do Comportamento descreve as diferentes modalidades dos fenômenos - físicos, vitais, e simbólicos- preservando a originalidade inerente a cada estrutura, e ressaltando que a dimensão vivente é "um modo de ser que somente pode ser conhecido adequadamente a partir de si mesmo" (BIMBENET, 2014, p.108). Com isto em mente, o empreendimento fenomenológico almeja descrever a vida como uma perspectiva original sobre o mundo. "A fenomenologia salienta a 'visada' do mundo, o ato subjetivo através do qual o mundo nos aparece" (BIMBENET, 2014, p.113)

Se por um lado a noção de subjetividade abre a via de uma descrição da experiência vivente a partir de si, por outro, é necessário, ainda, que esta subjetividade seja definida sob a insígnia do perspectivismo. Presente n'A Estrutura do Comportamento pelo viés da multiplicidade perspectiva humana, o tema do perspectivismo é fundamental para Bimbenet. Ele permite à fenomenologia inscrever-se no debate a partir da subjetividade animal e humana, sem preocupar-se em explicar os fenômenos pelos métodos de indução empírica. 
Por isso, todo problema da diferença é analisado, por Bimbenet, a partir da noção de perspectiva. Nessa medida, a vida animal é uma perspectiva absoluta e única. O animal somente é o seu próprio ponto de vista, um centro subjetivo que percebe apenas àquilo investido por seus interesses. A subjetivação do meio, por parte do animal, é radical, pois ela ocorre sob o comando dos a priori funcionais do organismo.

[...] [o animal] percebe perspectivamente, se entendermos com esta expressão um perspectivismo radical ou radicalmente unívoco. A percepção animal está destinada a uma perspectiva funcional que constitui sua origem focal; aquilo que ela apreende no exterior obedece a uma norma interna que prescreve seu sentido antecipadamente. (BIMBENET, 2014, p. 157-158)

Em outros moldes, o objetivismo científico concebe a natureza como uma série de acontecimentos exteriores entre-si e ligados por relações de causalidade. Consequentemente, o comportamento é definido como um acontecimento determinado causalmente por fatores de ordem física. Em suas discussões, Bimbenet (2014) questiona o pressuposto científico de um mundo previamente determinado, que independe das capacidades perceptivas do sujeito. A explicação do conhecimento animal como um modo de exploração de um mundo objetivo, previamente suposto, incorre em uma espécie de antropomorfismo, validado pela idéia de que os recursos cognitivos do organismo desvelam o mundo tal como ele é, em sua objetividade. Inversamente, a noção de perspectivismo visa descrever o "conhecimento" animal como um ato de ordem prática, e não cognitiva. De acordo com Bimbenet (2014, p. 132): "a inteligência animal se realiza na própria percepção muito mais como uma certa sagacidade do olhar do que como um exercício de reflexão".

$\mathrm{Na}$ obra inaugural de Merleau-Ponty o naturalismo científico está representado por figuras como Pavlov e Watson. No contexto contemporâneo, Bimbenet dirige suas críticas, principalmente, à etologia cognitiva. Este ramo do saber ocupa-se, especialmente, em fornecer um modelo da percepção animal calcado na cognição humana. O princípio básico assumido por esta disciplina é o de que as diferenças que separam a cognição animal da cognição humana são diferenças de grau, e não de natureza. Pressupõe-se, deste modo, uma linha contínua, sem rupturas, que iria dos animais aos seres-humanos. Nestes últimos, haveria um refinamento complexo das funções cognitivas. Certos autores, tais como Proust (2000), defendem a ideia de que determinadas espécies animais possuem capacidades representativas. As representações são indicadores que podem ser tanto naturais quanto convencionais. Um indicador está necessariamente atrelado a uma cadeia causal de acontecimentos. O fogo produz fumaça e a fumaça indica fogo (PROUST, 1995, p. 276). É equivalente afirmar que a capacidade do animal de receber, processar e estocar informação assemelha-se à nossa. Nesta lógica, através da capacidade de representar, ou seja, acessar determinados conteúdos mentais, o animal ajusta sua ação dentro dos parâmetros da informação representada e da informação atualmente 
recebida, ou de forma mais geral, dos conteúdos internos em face dos conteúdos externos. Esta aptidão, própria dos "viventes cognitivos" (PROUST, 2000), em projetar no exterior informações internas é o que os etologistas chamam de intencionalidade.

Ao tratarmos da intencionalidade animal a partir da noção de perspectiva, compreendendo-a como esta aptidão fundamental aos viventes de constituir um mundo próprio, selecionado de acordo com as demandas próprias do organismo, não estaríamos fadados a um gênero de representacionalismo, tal como disseminado pela etologia cognitiva? Essas normas, ou significações vitais, às quais nos referimos, não seriam, em última instância, representações mentais articuladas em outputs motores? De que maneira tratar a intencionalidade vivente permanecendo fiel à realidade biológica do organismo?

Uma das vias utilizadas por Bimbenet (2014) para escapar ao representacionalismo, e permanecer fiel à realidade biológica, refere-se ao paradigma da Gestalt. Este viés torna possível delimitar o problema do sentido a partir de uma perspectiva biológica e não cognitiva, sem recorrer ao conceito de representação e, sem desviar do propósito fenomenológico de descrever o caráter intencional da relação sujeito/mundo. Duas propriedades da forma assumem um papel fundamental na descrição da ação vital. Primeiramente, segundo a Psicologia da Gestalt, todo dado perceptivo se configura como relação figura-fundo. Aplicando este princípio ao âmbito da atividade vivente, temse que determinados estímulos destacam-se como figuras - objetos em primeiro plano- de acordo com as normas vitais do organismo, enquanto outros estímulos "preenchem" o fundo do campo sensorial, sem, no entanto, serem notados enquanto sinais. O dado percebido é selecionado como prioridade de acordo com as demandas vitais do animal. "A extração de uma figura a partir do fundo, em primeiro lugar, expressa diretamente o trabalho de seleção da tendência" (BIMBENET, 2014, p.135). Por exemplo, um animal que está com fome irá, momentaneamente, "recalcar" outros comportamentos que não estejam vinculados a essa tarefa específica. No animal, a perspectiva é "radicalizada" em torno de um valor funcional singular e, nessa medida, este "perspectivismo radical" pode ser definido como uma centralização subjetiva que polariza a universalidade do mundo transformando-o em uma particularidade pura. Os processos de figura-fundo representam um gênero de "recalcamento" originário, que funda a dialética vital do organismo com seu meio. A percepção animal se configura como uma dimensão essencialmente vital, isto é, ligada a problemas de ordem prática estabelecidos na intersecção entre as normas internas do organismo e as propostas do ambiente. A intencionalidade vital, em detrimento da intencionalidade representativa, deve ser entendida aqui como um gênero de concernimento prático e ativo que o animal possui de seu ambiente. Analogamente, encontramos este nível eminentemente prático de orientação em vários âmbitos da atividade humana, como nos esportes, por exemplo. O jogador de futebol orienta-se espacialmente através de certas direções do 
campo - o gol, a lateral- que não são lhe dadas como representações mentais, mas como linhas de força que norteiam suas ações. Segundo Merleau-Ponty (2006):

\begin{abstract}
O campo não lhe é dado, mas está presente para ele como o termo imanente de suas intenções práticas; ele e o jogador são um só corpo e o jogador sente, por exemplo, a direção do gol tão imediatamente quanto a vertical e a horizontal de seu próprio corpo. Não bastaria dizer que a consciência habita esse meio. Ela nada mais é, nesse momento, que a dialética do meio e da ação (p.263).
\end{abstract}

A segunda propriedade da forma refere-se ao seu caráter de generalidade e transponibilidade. Para Merleau-Ponty, a aprendizagem não é equivalente à repetição mecânica do que fora aprendido; pelo contrário, ela consiste na capacidade de adaptar diferentes soluções, ou ações, a situações comuns. Esta "transponibilidade" das formas aprendidas é vista, por exemplo, quando escrevemos em um quadro-negro. Por mais que os grupos musculares requeridos sejam diferentes de quando escrevemos em um papel, mantemos uma forma geral da nossa caligrafia. No caso do animal, sublinha Bimbenet (2014), a aprendizagem está vinculada à satisfação de uma necessidade específica. Nesse sentido, o reconhecimento de formas gerais, ou típicas, está relacionado com os a priori funcionais do organismo.

Sob outro ângulo, a psicologia cognitiva entende que esta "generalização" presente na percepção animal refere-se a uma espécie de "inteligência do ambiente". Para essa vertente, um animal "aprende" quando este atinge a capacidade de categorizar, ou generalizar os dados percebidos. A categorização, ou a classificação, diz respeito à aptidão em subsumir as informações extraídas em categorias, ou conceitos, que proporcionam um mapa ambiental para o organismo. No entanto, segundo Bimbenet (2014), a generalização do conhecimento representa o primeiro passo da interação do organismo em seu meio, e não o auge. A categoria não é posterior à percepção, pois todo percepto notado pelo animal já é assentado em uma significação funcional: comer, caçar, reproduzir-se. A seletividade, ou a abstração do dado, acompanha a generalização. Por isso, a generalização não consiste em uma fase final, em um ganho cognitivo; antes, a categorização animal está em estreita correlação com os valores funcionais atribuídos aos seus objetos de interesse. Isto significa que "a categoria ou o conceito se confunde simplesmente com os objetos que a instanciam" (BIMBENET, 2014, p.132). A possibilidade de perceber "formas típicas", ou gerais, é anterior à individualização dos dados percebidos. Assim, o ambiente é organizado, desde o princípio, em função de normas específicas.

É preciso interpretar de outra maneira esta generalidade: não como um tema abrindo a conduta a diferentes variações, mas sobretudo, como o recalcamento ativo destas variações, a subsunção forçada do diverso na unidade imperiosa de uma estrutura de comportamento (BIMBENET, 2014, 136) 
Embasando-se nestas duas características da forma- a composição figura-fundo e a generalização do dado- Bimbenet direciona-se a uma descrição da percepção animal como um fenômeno biológico. A ênfase recai nos processos de seleção e abstração dos dados sensíveis, explicados a partir de uma ação orientada por normas vitais. Nota-se, contudo, que a dimensão biológica não deve ser confundida com uma teoria fisiológica da percepção. Com o intuito de evitar o fisicalismo da Psicologia da Gestalt, uma alternativa é recorrer à Goldstein, o qual concebe a constituição da "boa forma" como uma atividade integrada do organismo, ou ainda, como a “tendência ao comportamento privilegiado" (GOLDSTEIN, 1983, p.410).

Compreendida como a busca por uma otimização comportamental, a perspectiva do animal obedece a este jogo de abstração e generalidade- o animal "recalca" tudo aquilo que não corresponde às determinações da necessidade e, ao mesmo tempo, o dado é percebido como generalidade, isto é, como indicador dos aspectos procurados pela norma vital. Uma tal redefinição da ação vital, realizada sob a ótica do perspectivismo, acarreta uma reformulação da própria ideia de intencionalidade. Tratase de uma "intencionalidade pura" (BIMBENET, 2014, p.168), à medida que o visado delimita-se como àquilo que fora investido de significação vital.

\begin{abstract}
O ponto de vista do animal é aquilo que torna visível: ao mesmo tempo, torna algo paupável, isto é, institui ativamente um ambiente, e vê, isto é, recebe passivamente as informações que lhe concernem. $\mathrm{O}$ pacto que um organismo assina com o seu entorno para dele fazer um ambiente funciona em mão dupla: o animal é inteiramente criador, ele somente perceberá aquilo que ele 'quiser' realmente perceber em função de suas necessidades; mas, ao mesmo tempo, este ambiente é encontrado pelo animal como existindo independentemente dele[...] Um vivente percebe as coisas que são, ao mesmo tempo (e todo problema está aí) para ele, sob a forma de capacidades práticas das quais ele decidiu o sentido e o valor e, fora dele, como recursos efetivos pertencentes ao mundo físico (BIMBENET, 2014, p.146)
\end{abstract}

Para que se compreenda a perspectiva como o núcleo da vida intencional, é preciso ultrapassar uma visão restritiva do perspectivismo. Em outras palavras, não se trata de entender a perspectiva apenas como o local individual ocupado por um organismo - seu situs. Se assim fosse, a perspectiva, ao invés de ser a abertura ao mundo, seria justamente aquilo que limitaria o animal dentro de certas determinações. Por isso "falar de um perspectivismo animal não é simplesmente dizer que um animal é designado a um situs (perceptivo e funcional)" (BIMBENET, 2014, p.146). Se o animal polariza o mundo de maneira radical é porque este vínculo intencional é primordial, nasce com a história da vida e forma com ela um verdadeiro pacto.

Bimbenet sugere que a própria noção de perspectivismo seja delimitada a partir da subjetividade animal.

É preciso ser um vivente para ver uma coisa sob um certo aspecto, na medida em que ser um vivente consiste precisamente em fazer aparecer aquilo que é a partir de um ponto de vista 
funcional e desde um certo interesse vital; a vida tal como nós a definimos confunde-se com o que, talvez mais claramente agora, assume a expressão de um perspectivismo (BIMBENET, 2014, p.139)

\section{A LÓGICA DO MÚLTIPLO E A QUESTÃO DA INTERSUBJETIVIDADE}

A perspectiva do animal é radical, isto é, ela está inteiramente mergulhada na unidade da norma. A lógica que a preside é a da unificação do sentido. $\mathrm{O}$ animal-sujeito de Bimbenet é o ser de uma perspectiva eminentemente funcional, tributária das significações vitais do organismo e, limitada ao seu próprio ponto de vista. Ao avaliar o tema da diferença antropológica sob o viés do perspectivismo nos deparamos com o conceito de multiplicidade perspectiva.

É essa possibilidade de expressões variadas de um mesmo tema, essa "multiplicidade perspectiva" que faltava ao comportamento animal. É ela que introduz uma conduta cognitiva e uma conduta livre. Tornando possíveis todas as substituições e pontos de vista, ela libera os 'estímulos' das relações atuais nas quais meu ponto de vista particular os prende, dos valores funcionais que as necessidades da espécie definidas para sempre lhes atribuíam (MERLEAU-PONTY, 2006, p.192)

Por meio de uma guinada arqueológica, o perpectivismo torna-se uma questão ontológica, que nos revela a origem vital da percepção humana. O sentir animal nos coloca frente a uma intencionalidade inteiramente polarizada por normas específicas. No entanto, se partimos da percepção animal é para, justamente, sublinhar que a percepção humana se configura segundo uma "lógica do múltiplo" (BIMBENET, 2014). Mesmo nos comportamentos dos símios antropóides, nossos parentes mais próximos, a relação com o objeto é mediada de acordo com esquemas funcionais delimitados. O objeto é investido pelo animal de uma significação funcional clara. Daí a dificuldade do animal em perceber que o mesmo objeto possui funções distintas. A seu modo, a visão humana é essencialmente plural, ela traz em si a possibilidade de perceber a mesma coisa sob diferentes aspectos. Não somente isso, pois o infinito leque de variações perspectivas permite nosso momentâneo desprendimento em direção a outrem. A percepção da criança nos oferece indícios de uma visada que é, necessariamente, intersubjetiva. "A criança que sabe indicar com o dedo [...] na verdade já conquistou o essencial de uma 'razão humana', esse espaço plural onde os diferentes aspectos das coisas corrigem-se uns aos outros" (BIMBENET, 2014, p.162). Quando dissemos que a noção de perspectiva não deve apenas indicar o espaço individual propriamente dito, é porque a percepção humana se constitui como a instauração de um campo intersubjetivo. O diálogo, por exemplo, representa bem este movimento de alternância perspectiva. Não é que sejamos um ponto de vista desencarnado, passível de flutuar sobre o mundo e dele possuir um olhar de sobrevoo. O conceito de multiplicidade perspectiva não representa o desenlace total do sujeito em relação ao seu ponto de 
vista, pelo contrário, ele frustra o olhar de sobrevoo ao encarnar a percepção como uma experiência intersubjetiva primordial. É por isso que Bimbenet (2014, p. 15) afirma que "o vivente humano pode mais ou menos desprender-se de si mesmo ou mais ou menos se descentrar na direção de seus congêneres". O perspectivismo humano nos impele a avaliar o problema da diferença antropológica no terreno da intersubjetividade.

\section{A ATENÇÃO CONJUNTA}

A multiplicidade perspectiva operante no seio da percepção humana nos remete, via direta, ao problema da constituição de um mundo comum. Em oposição à subjetivação radical do animal a particularização de seu ambiente- o perspectivismo humano nos oferece a chave de nossa crença na absolutidade do mundo, na medida em que a visada humana constitui-se, primordialmente, como intencionalidade compartilhada (BIMBENET, 2014). "Nós somos espontaneamente realistas porque o ser é, para nós, uma contribuição de todos” (BIMBENET, 2014, p.244).

Todo um campo teórico-experimental, envolvendo desde a psicologia do desenvolvimento até as neurociências, encontra na percepção infantil as raízes para a compreensão de nossa intersubjetividade. Um dos objetivos desses estudos em "cognição social” consiste em delimitar um fenômeno, já observado em crianças com menos de um ano, denominado "atenção conjunta". De modo geral, esta expressão diz respeito ao aspecto triádico das relações humanas, caracterizado pelo compartilhamento da atenção com outrem em torno de um mesmo núcleo comum. Até os seis meses de idade, a criança alterna sua atenção entre os corpos humanos e os objetos sem, contudo, formar uma relação triádica. O outrem humano e os objetos físicos não convergem, nesse sentido, para um mesmo cenário de ação. Nesse período, a criança não "conta" com o adulto como um ser capaz, por exemplo, de alcançar um objeto que se encontra distante dela. A percepção do objeto e a percepção do outro formam dois momentos distintos. A partir dos seis meses de idade, a percepção do objeto é integrada em seu contexto social. Conforme explica Bimbenet, a questão central da atenção conjunta não se resume apenas ao fato de ver a mesma coisa que outrem e, sim, de saber que o outro também percebe o mesmo objeto. Ao indicarmos algo para alguém, ou ao tecermos comentários verbais sobre alguma coisa, situamo-nos em um contexto social onde o outro está incluso como agente intencional. "Agentes intencionais são seres animados que têm objetivos e que fazem escolhas ativas entre os meios comportamentais disponíveis para atingir aqueles objetivos" (TOMASELLO, 2003, p. 94)

Bimbenet (2014) confere um lugar de destaque às publicações do psicólogo Michel Tomasello, dada suas contribuições à compreensão do fenômeno segundo um ponto de vista socialcognitivo. Para este autor, a atenção conjunta se define como uma "identificação precoce ao outro" 
(BIMBENET, 2014, p.247), que é refinada posteriormente através da aquisição do raciocínio instrumental, por volta dos nove meses de idade. Assim delimitada, a atenção conjunta aparece na criança humana como uma capacidade prática que se manifesta também como a partilha dos atos de perceber a mesma coisa.

No nível da antropogênese, o reconhecimento do outro humano constitui a base para o surgimento dos fenômenos sociais. Em termos evolutivos, o período de seis milhões de anos que nos separam dos grandes símios não é suficiente para explicar a amplitude das mudanças cognitivas e sociais, referentes à técnica humana. A passagem da fabricação de ferramentas à técnica industrial moderna representa um período relativamente curto na história da vida. Segundo Bimbenet (2014), em conformidade com Tomasello, somente um fator explica a velocidade e profundidade destas mudanças: a transmissão cultural. Mesmo que tal nível de comunicação seja encontrado nos animais, ele se manifesta como performances individuais que não são transmitidas para a continuidade da espécie. No caso dos seres-humanos, a transmissão cultural é acumulativa. O reconhecimento do outro como agente intencional é o fundamento necessário para a transmissão de comportamentos sociais, como os de cooperação e imitação. "Uma diferença biológica mínima, pois única- no caso, a capacidade de identificação ao congênere-, basta para produzir os máximos efeitos do lado não mais biológico, mas da sociogênese e da acumulação cultural” (BIMBENET, 2014, p.249). Observa-se, deste modo, que a temporalidade que rege a evolução humana não se constitui apenas no terreno da evolução natural; trata-se de uma temporalidade histórica e cultural.

A exclusividade da atenção conjunta nos seres-humanos e, logo, sua importância como critério hominizante, é questionável se analisarmos os comportamentos sociais dos grandes símios. Desde uma estruturação sensório-motora semelhante a nossa, esses animais exibem uma gama variada de condutas sociais. A etologia e a primatologia do último século mostram que os primatas não-humanos apresentam complexas estruturas relacionais, presentes desde a percepção do mundo físico, como a capacidade de categorizar objetos, até o surgimento de condutas "políticas". Os grandes símios formam alianças, resolvem problemas juntos, desenvolvem uma lógica de sociabilidade fundada na cooperação ou na dominação. Nesse quadro, tanto no que concerne à inteligência prática, quanto no que tange às capacidades sociais, o mundo dos grandes símios não parece tão distante do nosso. Em tom discordante, para Bimbenet (2014) é preciso situar a atenção conjunta na intersecção entre estas duas ordens, a percepção de objetos físicos e a percepção social. Esta proposta, calcada em uma análise estrutural, considera que enquanto estes tipos de inteligência não forem reciprocamente a expressão um do outro, a atenção conjunta permanecerá um fenômeno idêntico ao longo da escala evolutiva. 
Enquanto as duas séries da inteligência material e da inteligência social permanecerem paralelas, enquanto o domínio físico não for visado a partir do domínio social e que inversamente o grupo não seja vivido como um conjunto de espíritos voltados na direção do mesmo mundo, em suma, enquanto se permanece no interior de relações diádicas, tão complexas sejam elas, não nos aproximamos do acontecimento hominizante (BIMBENET 2014,p. 252)

Nesse sentido, ainda que sejam observados comportamentos de imitação ou de cooperação, a acumulação cultural demonstra-se um fenômeno raro. Segundo Bimbenet (2014), a postura da etologia frente a tais acontecimentos é generalizar as performances individuais transformando-as em características inerentes a toda espécie. Assim, o surgimento de um "comportamento surpreendente" assume dimensões estatísticas que não são comprovadas em todos os membros da espécie. Animais que foram criados em ambientes humanos apresentam comportamentos que não são típicos de sua espécie. A questão, de acordo com Bimbenet, é que a generalização de tais constatações não representa uma herança filogenética, herdada da evolução da espécie. Ocorre que, para além do “comportamento em si”, é preciso considerar qual função e, em qual contexto, presencia-se o aparecimento de determinada conduta. "Um pointing [ato de apontar] pode ser simplesmente 'imperativo', como é o caso nos chimpanzés ou nos gorilas, sem ser 'declarativo', como constatamos na criança a partir de doze meses" (BIMBENET, 2014, p. 254).

Os comportamentos sociais primitivos, as condutas de imitação e cooperação, exigem que o observador desprenda-se de seu ponto de vista dirigindo-se ao comportamento de outrem. Não é tanto a finalidade da tarefa realizada que está em questão, mas, na imitação, por exemplo, trata-se de captar a "lógica própria" das condutas de outrem. No caso dos chimpanzés, entretanto, os comportamentos de seus companheiros lhe são dados muito mais como ocasiões que estimulam a percepção de determinado objeto, do que como "comportamentos a serem imitados". Isto significa que a conduta alheia lhe serve apenas no sentido de reforçar determinado conjunto de estímulos. A atenção ao congênere não está no centro da aprendizagem, o que a torna uma aprendizagem "falsamente social" (BIMBENET, 2014, p.257). “O macaco observa um outro comendo cocos: o espetáculo dos cocos ao pé das árvores é em si um convite a brincar com os cocos, a manipulá-los, a eventualmente parti-los." (BIMBENET, 2014, p.257). Consequentemente, "uma descoberta eficaz pode permanecer letra morta, em função da ausência de uma atenção mais vigorosa com respeito ao congênere" (BIMBENET, 2014, p.260).

A imitação realizada pela criança, por outro lado, não está estritamente ligada à finalidade da situação. Diferentemente dos símios antropoides, na criança já se observa a imitação de comportamentos sem finalidade própria, que são essencialmente abstratos. Os aspectos afetivos do reconhecimento de outrem se sobressaem em relação a uma percepção funcionalmente restrita aos resultados da tarefa. A identificação com o outro se inscreve em um campo afetivo no qual é possível 
a existência de "apego sem razão" (BIMBENET, 2014, p.261). Eis, portanto o que a análise da imitação nos revela:

\begin{abstract}
Uma descrição precisa da imitação nos grandes símios chega então a dois comportamentos que são muito mais paralelos que convergentes. Uma coisa é visar cada um por si a mesma finalidade, fazendo coincidir por acaso diferentes momentos da ação, uma outra coisa bem diferente é se apropriar, através da observação direta, da perspectiva do congênere e da intenção prática que é sua (BIMBENET, 2014, p.261)
\end{abstract}

O seguinte relato pode nos esclarecer o posicionamento assumido por Bimbenet no que concerne ao sentido dos comportamentos sociais. Em 1953 fora documentado na ilha de Koshima, no Japão, a existência de uma prática entre os macacos que consistia em lavar batatas doces para lhes retirar a areia e, após esta primeira lavagem, era realizada uma outra lavagem na água do mar, com a finalidade de salgar o alimento. A hipótese da época destacava que tal mecanismo social fora disseminado por meio da imitação e do ensino. Nos anos 70, a interpretação deste fenômeno sofrera uma drástica alteração. Os pesquisadores notaram que a difusão de um novo comportamento pelo grupo demorava cerca de dois anos. Além disso, o número de animais capazes de realizar a tarefa não era um fator influente na transmissão da atividade para o resto do grupo. Deste modo, é possível explicar o aparecimento desta prática em um nível individual. O gênero de aprendizagem está mais na ordem de uma "facilitação social" do que, propriamente, da imitação ou do ensino. "São então as insuficiências da partilha social da inovação, muito mais que aquelas referidas ao seu caráter propriamente inovador, que mantém a cultura animal no estado de 'pré-cultura" (BIMBENET, 2014, p. 265).

Em síntese, sob o crivo da atenção conjunta, a intencionalidade animal revela plenamente sua dimensão "radicalizante", imersa em seu próprio ponto de vista. Não são apenas os comportamentos de imitação que encontram essa limitação. Todas as condutas que ocorrem no terreno da atenção conjunta esbarram nesta dificuldade, própria da percepção animal, em se colocar no lugar do outro. Nas tarefas que exigem cooperação, esta dificuldade de perceber o outro como agente intencional torna-se evidente. Por mais que o animal conceba seu companheiro como um "objeto animado", toda tarefa orbita em torno de seus próprios interesses. A aptidão para "lidar" com outrem, utilizar de sua força para ajudar a carregar uma caixa, por exemplo, não é suficiente para se caracterizar como um fenômeno de atenção conjunta, pois este demanda o desprendimento do próprio ponto de vista em direção ao outro. Nesse sentido, pode-se afirmar que, na interação com seus congêneres, está em jogo mais uma "utilização pragmática do outro" (BIMBENET, 2014, p.265) do que um reconhecimento genuíno de sua perspectiva. $\mathrm{O}$ gesto de apontar algo, aprendido pelo chimpanzé após quatrocentas tentativas, designa uma ação imperativa, onde a função do outro não é, tanto, a de partilha, mas a de servir como instrumento para seus interesses. $\mathrm{O}$ aspecto declarativo do gesto de apontar indica outra 
atitude em relação a outrem. Quando apontamos, compartilhamos do mesmo mundo, declaramos o objeto a um agente intencional.

\section{CONSIDERAÇÕES FINAIS}

Sob os auspícios conceituais da filosofia de Merleau-Ponty, especialmente sob a tutela do conceito de perspectivismo, intencionamos mostrar como o filósofo Etienne Bimbenet desenvolve uma abordagem fenomenológica voltada para a análise do que se convencionou chamar de problema da "diferença antropológica". Assim, frente às narrativas que "animalizam" o homem- como no caso da etologia cognitiva- ou ainda, face aos discursos humanistas que não problematizam o enraizamento vital da consciência, a proposta fenomenológica compreende que tanto a animalidade e a humanidade são perspectivas originais sobre o mundo. É preciso, portanto, descrevê-las a partir de si. Esta ênfase na experiência subjetiva não renega o passado vital da consciência, mas realça uma diferença que é de ordem estrutural e não substancial. Isto é, a ordem humana apresenta uma estrutura de comportamentos marcada pela virtualização do ver, princípio fundante da experiência perceptiva. O animal, como vimos, representa o contrário: a unificação do sensível, a polarização do mundo, a centralização do percebido a partir de si, de acordo com seus interesses vitais. Uma análise estrutural evita definir a singularidade humana pelo aparecimento da razão. A "razão" humana, para MerleauPonty, se constitui mais como um pacto corporal com o mundo, do que como uma atividade de apreensão intelectual. Nesse sentido, a percepção humana é regida por uma lógica do múltiplo, do virtual, do desprendimento. Enquanto a intencionalidade animal designa esta polarização do sensível, a intencionalidade humana é abertura a outrem e, portanto, é intencionalidade compartilhada. Por isso afirma Merleau-Ponty (2006, p. 271): “a palavra vida não tem o mesmo sentido na animalidade e na humanidade, e as condições da vida são definidas pela essência própria da espécie”.

\section{REFERENCIAS}

BIMBENET, E. O animal que não sou mais. Tradução Maurício José D’Escragnolle Cardoso. Curitiba: UFPR, 2014. (Trabalho original publicado em 2011)

GOLDSTEIN, K. La Sructure de l'organisme. Tradução E. Buckhartdt; J. Kuntz. Paris: Gallimard, 1983. (Trabalho original publicado em 1934)

MERLEAU-PONTY, M. A Estrutura do Comportamento. Tradução Márcia Valéria Aguiar. 1. ed. São Paulo: Martins Fontes, 2006. (Trabalho original publicado em 1942) 
PROUST, J. Intentionality and Evolution. Behavioural Processes, v. 35, p. 275-286, 1995.

PROUST, J. L'animal intentionnel. Terrain, v. 34, p. 23-36, 2000.

TOMASELLO,M. Origens culturais da aquisição do conhecimento humano. Tradução Cláudia Berliner Sao Paulo: Martins Fontes. 2003 (Trabalho original publicado em 1999).

$\begin{array}{ll}\text { Histórico } & \text { Recebido em: 24-10-2016 } \\ & \text { Aceito em: 16-11-2018 }\end{array}$

Agência de Fomento Capes 